\title{
Consenso colombiano de expertos sobre recomendaciones informadas en la evidencia para el manejo de la infección por SARS-CoV-2/COVID-19 en adulto mayor multimórbido con enfermedad renal crónica
}

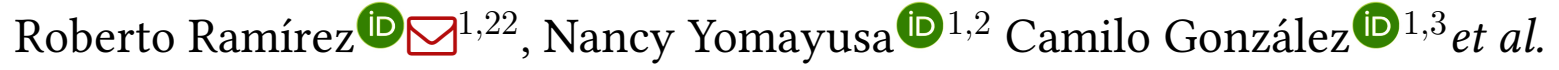 \\ ${ }^{1}$ Capítulo de nefrogeriatría, Asociación Colombiana de Nefrología e Hipertensión Arterial, Bogotá, Colombia. \\ ${ }^{2}$ Grupo de Investigación Traslacional IGEC, Unisanitas-Keralty, Bogotá, Colombia. \\ ${ }^{3}$ Unidad Renal Sanitas, Clínica Colsanitas, Bogotá, Colombia. \\ ${ }^{4}$ Fresenius Medical Care, Colombia. \\ ${ }^{5}$ Baxter, Colombia. \\ ${ }^{6}$ Universidad Simón Bolívar, Barranquilla, Colombia.
}

Recibido:

10/Oct/2020

Aceptado:

13/Abr/2021

Publicado:

05/Abr/2021

Lista completa de autores

Cómo citar: Ramírez R, Nancy N, González C, Yama E, Vargas JG, Rico J. et al. Consenso colombiano de expertos sobre recomendaciones informadas en la evidencia para el manejo de la infección por SARS-CoV-2/COVID-19 en adulto mayor multimórbido con enfermedad renal crónica. Rev. Colomb. Nefrol. 2021 8(2), e525. https:/doi.org/10.22265/acnef.8.2.525

Resumen

Introducción: la infección por SARS-CoV-2 es una pandemia con importante impacto en población adulta mayor con múltiples morbilidades.

Objetivo: desarrollar, mediante un consenso de expertos, recomendaciones informadas en evidencia para la prevención, diagnóstico y manejo de infección por SARS CoV2/COVID-19 en el paciente adulto mayor multimórbido con enfermedad renal crónica.

Métodología: a partir de la evidencia recolectada a través de una revisión de literatura en Pubmed, Embase y sociedades científicas, se formularon recomendaciones que fueron sometidas a la consulta de expertos en nefrología, geriatría y cuidados paliativos. La calidad de la evidencia se evaluó con herramientas en función del tipo de documento. Las recomendaciones aprobadas fueron clasificadas de acuerdo con su dirección y fuerza.

$\square$ Correspondencia: Asociación Colombiana de Nefrología e Hipertensión Arterial, Universidad Santiago de Cali, sede Pampalinda, Cali, Colombia. Correo electrónico: robertoramire5@hotmail.com 
Resultados: 22 expertos declararon su conflicto de interés y diligenciaron la herramienta de consulta entre el 02 y el 10 de agosto del 2020. El porcentaje de acuerdo por cada recomendación osciló entre el 90,9 y $100 \%$. Se presentan 32 recomendaciones para el manejo de la infección por SARS-CoV-2 en paciente adulto mayor multimórbido con enfermedad renal crónica.

Conclusión: las recomendaciones formuladas orientan a la toma de decisiones de los profesionales de la salud involucrados en la atención de pacientes mayores con enfermedad renal crónica y otras morbilidades que presentan infección por SARS-CoV-2.

Palabras clave: infecciones por coronavirus, anciano, insuficiencia renal crónica, multimorbilidad, covid-19, paliativo.

\title{
Colombian consensus of experts on evidence-informed recommendations for the management of SARS-CoV-2 / COVID-19 infection in multimorbid older adults with chronic kidney disease
}

\begin{abstract}
Introduction: SARS-CoV-2 infection is a pandemic with a significant impact on the elderly population with multiple morbidities.

Objective: To develop evidence-informed recommendations for the prevention, diagnosis, and management of SARS CoV2 / COVID-19 infection in multimorbed elderly patients with chronic kidney disease, through a consensus of experts.

Methodology: Based on the evidence collected through a literature review in Pubmed, Embase and scientific societies, recommendations were formulated that were submitted to the consultation of experts in nephrology, geriatrics and palliative care. The quality of evidence was evaluated with tools based on the type of document. The approved recommendations were classified according to their direction and strength.

Results: Twenty-two experts declared their conflict of interest and filled out the consultation tool between August 02 and 10, 2020. The percentage of agreement for each recommendation ranged between 90.9 and $100 \%$.Thirty-two recommendations are presented for the management of SARS-CoV-2 infection in multimorbed elderly patients with chronic kidney disease.

Conclusion: The recommendations formulated guide the decision-making of health professionals involved in the care of elderly patients with chronic kidney disease and other morbidities with SARSCoV-2 infection.
\end{abstract}

Keywords: Severe acute respiratory syndrome coronavirus 2, aged, frail elderly, kidney disease. 


\section{Tabla de contenidos}

Página

Introducción

4

Metodología

Tratamiento de comorbilidades

¿Se deben continuar los ARA-2/iecas a

las dosis indicadas en estos pacientes?, ¿se debe modificar su dosificación?, ¿cuándo se suspenden los ARA-2/iecas? . . . . . . . Recomendaciones ........ 7

Terapia de soporte renal

¿Cuándo se define suspender la diálisis en un paciente adulto multimórbido con Covid-19? . . . . . . . . Recomendaciones .......

\section{Remisión a urgencias}

Un paciente con síntomas fuertes (tos, fiebre, malestar gastrointestinal), $¿$ debe dirigirse primero a urgencias o a la unidad renal? . . . . . .

¿Cuáles son las indicaciones renales para enviar un paciente con ERC (especialmente estadios 4 y 5) a urgencias de hospital de tercer nivel? . . . . . . . . . .

Recomendaciones .......

Transporte

Un paciente con síntomas fuertes, ¿debe transportarse con otros pasajeros? . . . . . . . . . . . .

Unidad de cuidados intensivos

¿Cuáles son los criterios para requerir hospitalización en UCI de un paciente con ERC en estadio 5? . . .

¿Cuál es la utilidad de escalas de fragilidad, Karnofsky y de Charlson, en esta emergencia para la orientación de un paciente con ERC avanzada que requiere UCI? . . . 10 Recomendaciones ......... 12
10

10

Reanimación cardiopulmonar

¿Cuándo se considera iniciar reanimación cardiopulmonar avanzada en un adulto mayor multimórbido con Covid-19? . . . . . . . . . . 13 Recomendaciones . . . . . . . 14

Salud mental

¿Cómo prevenir o tratar en casa el estrés postraumático asociado a la pandemia? . . . . . . . . 14 Recomendaciones ........ 15

Actividades ocupacionales

¿Cuáles son las recomendaciones para las actividades a realizar en casa del adulto mayor con comorbilidades? . . . . . . . . . . 15 Recomendaciones ........ 15 8

Contribución de los autores

Conflicto de intereses

Independencia editorial

Grupo desarrollador

Anexos

Anexo A. Evaluación de calidad de documentos incluido . . . . . . . 27

Anexo B. Resultados de la consulta por cada recomendación . . . . . . . 32 


\section{Introducción}

En Colombia, la enfermedad renal es una condición frecuente, se estima que aproximadamente el $10 \%$ de la población tiene algún grado de enfermedad renal y cerca del $56 \%$ de la población en diálisis es mayor de 60 años, según el informe de Cuenta de Alto Costo para el $2018[1]$.

La edad y las comorbilidades se han descrito como factores de riesgo y pronóstico de Covid-19 [2,3]. En el informe de hospitalización en EE. UU., a marzo del 2020, emitido por el CDC, el 74,5\% de los pacientes tenía 50 años o más y la tasa de hospitalización en mayores de 65 años fue de 13,8 por cada 100.000 habitantes [4].

La hipertensión se ha reportado hasta en el $57 \%$ de pacientes con Covid-19, seguido de obesidad (41\%), diabetes (34\%) y enfermedad coronaria $(8 \%)[5,6]$.

Hallazgos semejantes se han reportado para pacientes con enfermedad renal crónica (ERC) [7-10]; sin embargo, no está claramente definida la comorbilidad o comorbilidades específicas que inciden en la progresión de Covid-19 [11].

Se ha reportado que el $71 \%$ de adultos mayores con Covid-19 cursan con síndrome de enfermedad respiratoria aguda, el $20 \%$ con lesión renal aguda, el $33 \%$ con lesión cardíaca y el $15 \%$ con disfunción hepática [12]. La mortalidad en mayores de 60 años alcanza cifras hasta de $81 \%$, dependiendo la gravedad de Covid-19, y de si requieren ingreso a unidad de cuidado intensivo y soporte vital $[6,13]$.

Por lo tanto, en el adulto mayor multimórbido, considerado como población especial, que generalmente es frágil y tiene polifarmacia, su cuidado se presenta como un reto para la comunidad médica mundial en la coyuntura de la pandemia por Covid-19 y se hace necesario manifestar una postura desde el colectivo experto en nefrología y geriatría.

El objetivo del estudio fue generar recomendaciones basadas en evidencia sobre el manejo de adultos mayores multimórbidos con ERC que cursan con infección por Covid-19, a partir de un consenso de expertos en nefrología, geriatría y cuidados paliativos.

Dada la reciente aparición de la enfermedad y las incertidumbres que aún permanecen y que son materia de investigación, este manuscrito se considera un documento vivo que deberá ser actualizado en la medida en que se disponga de nueva información. 


\section{Metodología}

El grupo desarrollador del consenso y el colectivo experto definieron las preguntas de interés. Se realizó una revisión rápida de literatura en bases de datos en Pubmed y Embase. Además, se consultaron sociedades científicas y sitios oficiales de desarrolladores de guías de práctica clínica (GPC). Los términos empleados en las búsquedas fueron: frail elderly, older adult, elderly, renal disease, kidney disease, SARS-CoV-2, Covid, mental health, cardiopulmonary, resuscitation y Karnofsky, Charlson. La búsqueda se realizó hasta el 29 de mayo del 2020.

Para la evaluación de la calidad de los estudios se aplicaron: AGREE II para GPC, AMSTAR2 para revisiones sistemáticas y metaanálisis, RoB para ensayos clínicos, New Castle Otawa para estudios observacionales (cohortes o casos y controles) y la herramienta del Joanna Briggs Institute para series de casos o reportes de caso. Otros tipos de documentos fueron considerados de acuerdo con su pertinencia para resolver las preguntas. La evaluación de calidad por cada documento incluido se presenta en el anexo A.

Los hallazgos de la revisión se presentan a manera de resumen de evidencia, a través de síntesis narrativa, siguiendo recomendaciones del Joanna Briggs Institute [14] y, a partir de estos, el grupo desarrollador con participación de especialistas en nefrología, geriatría y cuidados paliativos formulan recomendaciones preliminares.

El colectivo se consultó entre el 02 y el 07 de agosto del 2020, a través de una herramienta en línea. Los expertos manifestaron su acuerdo o desacuerdo por cada recomendación preliminar, incluso realizaron observaciones y justificaciones del desacuerdo. Para cada recomendación se requirió aprobación del colectivo experto en al menos un $70 \%$ entre el total de personas que respondieron a dicha

Las recomendaciones fueron clasificadas según su dirección y fuerza recomendación, los hallazgos se presentan en el Anexo B. A pesar de ser considerado un consenso modificado del método Delphi, no fue necesaria su realización al tener en cuenta el acuerdo obtenido para cada recomendación en la consulta en línea.

Las recomendaciones fueron clasificadas según su dirección y fuerza [15]. La dirección fue a favor o en contra de la intervención o actuación declarada en la recomendación. La fuerza de las recomendaciones fue graduada en dos categorías: fuerte y débil, al considerar calidad de evidencia, balance de riesgos y beneficios, consumo de recursos o disponibilidad en el contexto y observaciones emitidas por el colectivo experto. Una recomendación fuerte fue definida en 
tanto los clínicos consideraran que la conducta promovida debe ser implementada en la mayor parte de los pacientes; mientras que una recomendación débil implicó que los expertos clínicos reconocieran disponibilidad de otras opciones apropiadas para distintos pacientes y, en este caso, el paciente debería ser orientado a alcanzar la decisión basada en sus preferencias.

\section{Tratamiento de comorbilidades}

Los inhibidores de la enzima convertidora de angiotensina (Iecas) y ARA-2 son medicamentos indicados para el tratamiento de hipertensión, ERC proteinúrica e insuficiencia cardíaca, síndrome nefrótico y nefropatía diabética [16].

La posible asociación de ERC con presentaciones graves de Covid-19 y muerte ha sido explicada hasta ahora por la afinidad del virus SARS-CoV-2 con la enzima convertidora de angiotensina 2 (ECA-2) [17,18], por lo cual el uso rutinario de iecas o antagonistas de receptor de angiotensina 2 (ARA-2) ha sido controvertido y basado en especulaciones, como lo exponen Williams y Zhang [18].

\section{¿Se deben continuar los ARA-2/iecas a las dosis indicadas en estos pa- cientes?, ¿se debe modificar su dosificación?, ¿cuándo se suspenden los} ARA-2/iecas?

En la cohorte retrospectiva de pacientes ingresados al Hospital Central de Wuhan, reportada por Li et al. [19], donde se analizó la exposición a antihipertensivos (IECA, ARA-2) para manejo de comorbilidades, no se encontró diferencia en los desenlaces de gravedad de Covid-19 y mortalidad.

De la misma manera, en el estudio de Abajo et al. [20] en población española, el uso de iecas no aumentó el riesgo de hospitalización por Covid-19 (OR: 0,94, IC $95 \%$ 0,77 a 1,15), tampoco el riesgo de desarrollar complicaciones graves o muerte (OR: 1,08, IC $95 \%$ 0,80 a 1,47); además, en paciente con diabetes y Covid-19 el uso de iecas y ARA-2 tuvo menos posibilidad de desenlace fatal (OR: 0,53 IC $95 \% 0,34$ a 0,80).

En el estudio retrospectivo de Peng et al. [21], realizado en pacientes con enfermedad cardiovascular y Covid-19, se compararon pacientes críticos con un grupo general y no se encontraron diferencias en la proporción de pacientes con antihipertensivos entre sobrevivientes y pacientes con desenlaces fatales. 
Sociedades científicas como la Sociedad Europea de Cardiología, Hipertensión Canadá, la Sociedad Cardiovascular Canadiense, la Asociación Renal del Reino Unido, la Sociedad Internacional de Hipertensión, la Sociedad Europea de Hipertensión, la Asociación Americana del Corazón, la Sociedad Colombiana de Nefrología e Hipertensión, la Sociedad Italiana de Cardiología, la Asociación Colombiana de Infectología y la Sociedad Italiana de Hipertensión Arterial han sugerido continuar los tratamientos, al menos hasta que exista evidencia que respalde una conducta diferente [22, 24]. En suma, algunos autores [13, 16, 25, 26] exponen que la suspensión de regímenes basados en estos medicamentos podrían generar diferentes desenlaces en salud en función de la patología para la cual fueron indicados, además de un incremento de recursos sanitarios.

La modificación o la suspensión de tratamientos con iecas y ARA-2 no tienen soporte científico hasta la fecha [27]. Algunos autores [10,28] coinciden en sugerir análisis individualizados que tengan en cuenta la condición de base que justifica la indicación del medicamento y el estado actual del paciente. Al respecto, el Hospital de Massachusetts sugiere considerar la suspensión de estos medicamentos ante daño renal agudo, hipotensión o alguna otra contraindicación, con la salvedad de reiniciar tan pronto como sea posible [29].

\section{Recomendaciones}

- Se recomienda continuar esquemas de tratamiento basados en IECA y ARA-2 en pacientes con indicación para su uso.

\section{A favor fuerte}

- En casos de daño renal agudo, hipotensión o contraindicación de uso, se recomienda suspender temporalmente los IECA y ARA-2.

\section{En contra fuerte}

- Se recomienda considerar la patología de base que justifica el uso del medicamento y el estado actual del paciente para considerar la modificación o la suspensión temporal del tratamiento instaurado.

\section{A favor fuerte}

- Se recomienda informar a los pacientes sobre su tratamiento y alentarlos a no cambiar o suspender la medicación, a menos que sea indicado por el médico tratante.

\section{A favor fuerte}




\section{Terapia de soporte renal}

\section{¿Cuándo se define suspender la diálisis en un paciente adulto multi- mórbido con Covid-19?}

Es escasa la información respecto a las indicaciones de suspensión de soporte renal en paciente adulto multimórbido con Covid-19; sin embargo, vale la pena considerar al igual que para el inicio de la terapia, aspectos como la esperanza de vida, los riesgos y los beneficios de la terapia de soporte renal (TST), la calidad de vida y las preferencias de los pacientes y cuidadores [30].

Al tener en cuenta que en el curso de la pandemia puede requerirse priorizar recursos para intentar preservar la mayor cantidad de personas, la gravedad y el pronóstico de la enfermedad son aspectos relevantes a considerar [31,32].

Se recomienda la aplicación de los criterios Necpal, los cuales son un instrumento que identifica varios parámetros con valor pronóstico, para la identificación oportuna de personas en situación de enfermedad crónica avanzada y necesidad de cuidados paliativos. Es una herramienta clínica y factible en la toma de decisiones clínicas. La identificación de parámetros según la enfermedad, la severidad, el estado de fragilidad y el estado específico de progresión según patología, nos permite identificar a

Se recomienda considerar el pronóstico del paciente y realizar análisis individualizado pacientes candidatos a cuidado paliativo [33].

\section{Recomendaciones}

- Se recomienda considerar el pronóstico del paciente y realizar análisis individualizado de los riesgos y los beneficios de la TST, además de las preferencias de los pacientes y sus cuidadores, frente a las opciones de cuidado en circunstancias de mal pronóstico o final de la vida.

\section{A favor fuerte}

- Se sugiere suspender la hemodiálisis en pacientes que cumplan los criterios clínicos y analíticos de mal pronóstico, independientemente de su edad, según los criterios de Necpal.

\section{En contra fuerte}




\section{Remisión a urgencias}

Un paciente con síntomas fuertes (tos, fiebre, malestar gastrointestinal), ¿debe dirigirse primero a urgencias o a la unidad renal?

Esta pregunta fue abordada implícitamente en [63]: Hemodiálisis, y las recomendaciones al respecto se encuentran detalladas en la sección de triaje y clasificación.

\section{¿Cuáles son las indicaciones renales para enviar un paciente con ERC (especialmente estadios 4 y 5 ) a urgencias de hospital de tercer nivel?}

Las indicaciones de remisión a urgencias u hospitales se recomiendan para pacientes con cuadro clínico grave mediante la evaluación clínica de marcadores de mal pronóstico (disnea, taquipnea, taquicardia) o la aplicación de scores de gravedad. Se sugiere evitar la remisión de pacientes con ERC sin signos de alarma, como medida de prevención de contagio y de optimización de servicios de urgencias [17,34]. No se conocen criterios renales específicos para remisión de pacientes con ERC en el marco de la pandemia por Covid-19.

La información disponible resalta la necesidad de que los pacientes en diálisis confirmados con Covid-19 continúen en la cohorte, al menos siete días o hasta su recuperación, en las unidades renales o de diálisis asignadas [35].

\section{Recomendaciones}

- Se recomienda evitar la remisión a servicios de urgencias para pacientes con ERC, a menos de que exista un empeoramiento de la condición general o de condiciones como pielonefritis, trauma renal, eventos vasculares en arteria o vena renal o trastornos hidroelectrolíticos que requieran monitorización continua, los cuales no puedan ser manejados en las unidades renales o de diálisis.

En contra fuerte

\section{Transporte}

\section{Un paciente con síntomas fuertes, ¿debe transportarse con otros pasa- jeros?}

Esta pregunta fue abordada implícitamente en [63]: Hemodiálisis, y las recomendaciones al respecto se encuentran detalladas en la sección: "Transporte de pacientes". 


\section{Unidad de cuidados intensivos}

\section{¿Cuáles son los criterios para requerir hospitalización en UCI de un paciente con ERC en estadio 5?}

Esta pregunta fue abordada en [63]: Hemodiálisis, y las recomendaciones al respecto se encuentran detalladas en la sección: "Requerimiento de cuidado crítico".

\section{¿Cuál es la utilidad de escalas de fragilidad, Karnofsky y de Charlson, en esta emergencia para la orientación de un paciente con ERC avan- zada que requiere $\mathrm{UCI}$ ?}

La evidencia disponible sugiere que la función física deteriorada podría ser considerada como un factor pronóstico, basado en hallazgos previos de adultos mayores que cursan con enfermedades respiratorias, por lo que el índice de Barthel tendría una función importante en la categorización del riesgo de pacientes con Covid-19 e incluso podría anticiparse a desenlaces fatales en población geriátrica [36].

La fragilidad definida como un síndrome geriátrico que se caracteriza por estado de vulnerabilidad, dado por la disminución de las reservas fisiológicas al estrés, lo que lleva a mayor probabilidad de enfermar, institucionalización y estancia hospitalaria prolongada, se ha relacionado con morbilidad y mortalidad en adulto mayor, y su prevalencia en paciente con ERC se ha estimado hasta en el $73 \%$ de los casos [37-39].

Se ha reportado en la literatura que pacientes con función renal disminuida (tasa de filtración glomerular estimada $<30,0 \mathrm{~mL} / \mathrm{min} / 1,73 \mathrm{~m}^{2}$ ) y comorbilidades tienen mayor posibilidad de fragilidad, en el caso de diabetes se reportó un odds ratio (OR) de 2,76 (IC $95 \%$ 1,21 a 8,24 ) y para hipertensión de 2,53 (IC $95 \%$ 1,45 a 5,12) [40].

NICE ha sugerido la medición de la fragilidad para todos los adultos a través de la escala de fragilidad clínica (CFS), considerando comorbilidades y la opinión de diferentes especialistas [41]. De la misma manera, Montero-Odasso et al. [42] han sugerido considerar la edad, las preferencias del paciente y la escala de fragilidad, estimando el estado del paciente dos semanas antes del inicio de síntomas para orientar la conducta clínica.

Se recomienda la identificación rutinaria de la fragilidad en el adulto mayor con ERC y comorbilidad por Covid-19, dado que estudios previos han identificado cómo este síndrome 
geriátrico juega un rol fundamental en la mortalidad, la CFS nos ayuda a determinar la mortalidad del paciente adulto mayor al separar los grupos en menor o mayor de 6, los grupos con una escala de fragilidad mayor a 6 tenían una tasa de mortalidad más grande durante la hospitalización, sin observarse mortalidad en los grupo con CFS 1, 2, 3 y 4; sin embargo, los pacientes con CFS de 5 presentaron una baja tasa de mortalidad $(8,3 \%)$ en comparación con CFS $6(29,2 \%)$ y CFS 7-8 (60\%). Los análisis de regresión logística revelan que un incremento de la fragilidad se correlaciona con la mortalidad, cuando se compara con CFS de 5 que fue un predictor independiente de mortalidad según el valor de misma (CFS 6: OR. 4,2 IC $95 \%$ 1,61 a 12,73; CFS 7-8: OR 17,99, IC $95 \%$ 5,36 a 60,34) de institucionalización y muerte (CFS 6: OR 5,11, IC $95 \%$ 1,97 a 13,27; CFS 7-8: OR 15,87, IC $95 \%$ 5,04-49,95) a los 12 meses poshospitalización [43].

Dueñas et al. [44] sugieren emplear la CFS para orientar la decisión clínica en pacientes adultos mayores con Covid-19. Estos autores sugieren que pacientes con puntuaciones entre 1 y 4 se beneficien de ingreso a UCI y, por ende, de terapia de reemplazo renal, a menos que exista una voluntad anticipada diferente; para puntuaciones entre 6 y 9 las intervenciones deberían ser dirigidas al control de síntomas y manejo médico no invasivo, evitando el ingreso a UCI.

En el estudio prospectivo de Le Maguet et al. [45] se incluyeron 196 pacientes mayores de 65 años, entre los cuales la fragilidad estuvo presente en el $41 \%$. Dentro de los factores de

Se debe notificar de forma
prioritaria para estudio de casos
relacionados

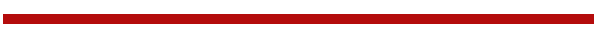
riesgo para mortalidad en la UCI se encontró el fenotipo de fragilidad (FP) (HR: 3,3, IC $95 \%$ 1,6 a 6,6), el sexo masculino (HR: 2,4, IC $95 \%$ $1,1$ a 5,3$)$, antecedente de paro cardíaco previa admisión (HR: 2,8, IC $95 \%$ 1,1 a 7,4), SAPS (Simplified Acute Physiology Score) mayor a

46 e injuria cerebral en la admisión (HR: 2,6, IC $95 \%$ 1,2 a 5,3). Los factores de riesgo para mortalidad a seis meses fueron CFS mayor a 5 (HR: 2,4, IC $95 \% 1,49$ a 3,87) y SOFA $\geq 7$ (HR: 2,2 IC $95 \% 1,35$ a 3,64).

Es de vital importancia identificar el adulto mayor en terapia de reemplazo renal que se encuentra institucionalizado, dado que al pertenecer a un conglomerado las instituciones de larga estancia tienen mayor prevalencia de fragilidad, comorbilidad y, por ende, mayor mortalidad por Covid-19 en caso de contagio masivo, como ha sido reportado ampliamente en países europeos y EE.UU., por lo tanto se debe notificar de forma prioritaria para estudio de casos relacionados y cerco epidemiológico [46]. 
La serie de casos de Richardson et al. [6] incluyó 5.700 pacientes con Covid-19 hospitalizados en Nueva York, a quienes se evalúo con el índice de comorbilidad de Charlson, el cual predice la supervivencia en 10 años a partir de la edad y presencia de comorbilidades. Se encontró una puntuación media de cuatro puntos que se traduce en supervivencia en 10 años de $53 \%$.

\section{Recomendaciones}

- Se recomienda la medición de funcionalidad y fragilidad en el adulto mayor con Covid-19 y considerar sus hallazgos en la actuación clínica.

\section{A favor fuerte}

- Se recomienda el uso del índice de Barthel como herramienta estandarizada y pragmática en la medición de la funcionalidad del adulto mayor.

\section{A favor fuerte}

- Se recomienda el uso de escalas de fragilidad como la escala Frail o la CFS en pacientes con Covid-19 y ERC, con base en la situación clínica en la que se encontraban dos semanas antes de los síntomas de infección por Covid-19, para orientar la conducta clínica en UCI.

\section{A favor fuerte}

- Se sugiere la aplicación del índice de Charlson como herramienta pronóstica en pacientes con Covid-19 y ERC, cuando la CFS se encuentre en puntuaciones entre 1 y 4 , estos pacientes se benefician de ingreso a UCI y soporte renal, evaluando siempre si existe una voluntad anticipada.

\section{A favor fuerte}

- Se sugiere que para pacientes con puntuación en CFS igual a 5, sea el geriatra quien realice una evaluación multidimensional en los diferentes dominios (médico, funcional, cognición, afecto, riesgo social) para definir los objetivos terapéuticos en cada persona mayor. En caso de no contar con este recurso humano, se recomienda realizar un análisis por equipo interdisciplinario, teniendo en cuenta la severidad de la patología y las voluntades anticipadas en la toma de decisiones.

\section{A favor fuerte}

- En el caso de pacientes con puntuaciones en CFS entre 6 y 9 se recomienda evitar el ingreso a UCI y orientar la práctica clínica hacia el control de síntomas y el manejo médico no invasivo.

\section{En contra fuerte}


- Se sugiere que los adultos mayores institucionalizados reciban el mismo enfoque en la toma de decisiones según la CFS.

\section{A favor fuerte}

- Se recomienda informar al paciente acerca del mecanismo de toma de decisiones, basado en la CFS y teniendo en cuenta el riesgo de contagio masivo en los centros de protección social.

\section{A favor fuerte}

\section{Reanimación cardiopulmonar}

La información disponible indica que cerca del $5 \%$ de los pacientes Covid-19 cursan con presentaciones graves o severas de la enfermedad y requieren manejo en unidad de cuidado intensivo (UCI) y soporte vital [47].

\section{¿Cuándo se considera iniciar reanimación cardiopulmonar avanzada en un adulto mayor multimórbido con Covid-19?}

La edad, la presencia de comorbilidades y la necesidad de soporte vital son considerados factores pronósticos de la enfermedad. Además, se ha encontrado reducción en la supervivencia a 10 años en pacientes con Covid-19 [5,6], condiciones que en el adulto mayor multimórbido son crucialmente importantes frente a la toma de decisiones de actuación clínica en situaciones complejas como paro cardíaco. Otro punto a tener en cuenta es la denominación de la reanimación cardiopulmonar, la intubación y la ventilación mecánica como procedimientos generadores de aerosoles que pueden favorecer la trasmisión del virus por SARS-CoV-2 y, por tanto, imponen un alto riesgo de contagio para trabajadores de la salud [48].

En consideración con lo anterior, algunos autores proponen evitar la reanimación cardiopulmonar avanzada en pacientes con sospecha o confirmación de Covid-19, basado en el análisis de riesgo-beneficio del

\section{la disponibilidad y al uso estricto de elementos de protección personal} procedimiento [49]. Existe un acuerdo en recomendar medidas preventivas de paro cardíaco que incluyen la identificación temprana de pacientes con enfermedades agudas y el uso de herramientas de pronóstico (NEWS). Chong et al. [50] proponen emplear como medida objetiva para definir dicha conducta, la puntuación obtenida en la CFS, basados en hallazgos previamente publicados por ellos, en los que puntuaciones de seis o más se asociaron con desenlace fatal. Además, se resalta 
la necesidad de exploración de voluntades anticipadas [51]. En Colombia, la Ley 1733 de 2014 les otorga a los pacientes con enfermedades en fase terminal, crónicas, degenerativas e irreversibles, el derecho a cuidados paliativos y a desistir voluntaria y anticipadamente a tratamientos innecesarios.

Otro aspecto sugerido para ser considerado en su realización corresponde a la disponibilidad y al uso estricto de elementos de protección personal que incluya protección para los ojos, respiradores N95 o filtro superior, guantes y batas [48,52].

\section{Recomendaciones}

- En el paciente adulto mayor multimórbido con sospecha o confirmación de Covid-19, con resultado en CFS $\geq 6$ se sugiere no realizar reanimación cardiopulmonar, al tener en cuenta factores pronósticos.

\section{En contra fuerte}

- En el paciente adulto mayor multimórbido con sospecha o confirmación de Covid-19, con resultado en CFS igual a 5, la decisión de reanimación debe ser soportada en una evaluación geriátrica integral.

\section{A favor fuerte}

- Se sugiere informar al paciente y a la familia sobre las decisiones de no reanimación.

\section{A favor fuerte}

- Se sugiere indagar las voluntades anticipadas en casos de mal pronóstico que no sea reversible.

\section{A favor fuerte}

\section{Salud mental}

\section{¿Cómo prevenir o tratar en casa el estrés postraumático asociado a la pandemia?}

Existe preocupación por la salud mental relacionada con la pandemia y las medidas implementadas para su control. Se ha reportado depresión, ansiedad, síntomas asociados a estrés postraumático y otras condiciones psicológicas en el 53,8\% de las personas, debido al estrés que implica la posibilidad de contagio, el aislamiento, el pronóstico de la enfermedad, la privación de ingresos y el sistema de salud, con mayor frecuencia de presentación en mujeres, adultos mayores de 60 años y personas con formación académica superior $[53,54]$. 
Estrategias implementadas en países que han superado la pandemia incluyen la información actualizada y constante a toda la población desde los gobiernos, en la habilitación de canales oficiales, la identificación de grupos de alto riesgo para intervenciones tempranas, monitoreo y notificación de síntomas psicológicos, hasta seguimiento de programas de salud mental a través de llamadas telefónicas, mensajes, videollamadas, chats y foros [54-57].

\section{Recomendaciones}

- Se recomienda identificar pacientes con alto riesgo de presentar condiciones psicológicas debido al estrés de la pandemia, teniendo en cuenta edad, comorbilidades, ocupación y apoyo social, con el fin de iniciar intervenciones tempranas.

\section{A favor fuerte}

- Se recomienda el acompañamiento de trabajo social para pacientes en soledad.

\section{A favor fuerte}

- Se recomienda el uso de herramientas tecnológicas que faciliten la realización de las intervenciones.

\section{A favor fuerte}

\section{Actividades ocupacionales}

\section{¿Cuáles son las recomendaciones para las actividades a realizar en casa del adulto mayor con comorbilidades?}

Las medidas de aislamiento obligatorio decretadas por muchos gobiernos para la prevención de contagio de SARS-CoV-2 han generado modificaciones en el estilo y los hábitos de vida, lo cual se ha identificado como un detonante de condiciones mentales [57]. Al respecto, la información existente propone mantener o generar rutinas para mantener actividad física y mental, a través del desarrollo de actividades cognitivas y sociales apoyadas de herramientas tecnológicas [58].

\section{Recomendaciones}

- Se recomienda continuar los hábitos de vida en la medida de lo posible o generar una nueva rutina durante la pandemia por Covid-19.

\section{A favor fuerte}


- Se recomienda incentivar el autocuidado en el adulto mayor.

\section{A favor fuerte}

- Se recomienda la realización de actividades físicas y cognitivas ajustadas a la edad y la condición física.

\section{A favor fuerte}

\section{Sexualidad}

En la editorial publicada por Wu et al. se hace un llamado a la identificación temprana de alteraciones urogenitales masculinas, especialmente en pacientes jóvenes, debido al potencial daño de hormonas masculinas a causa de la infección por SARS-CoV-2 [59].

\section{¿Cuáles son las recomendaciones de sexualidad en el paciente adulto mayor multimórbido con ERC?}

Durante la pandemia se han emitido algunas recomendaciones relacionadas con la conducta sexual segura. Algunos autores invitan a tener en cuenta las formas potenciales de transmisión del virus SARS-CoV-2, incluyendo el contacto directo de saliva, moco y heces, por lo tanto, se sugiere evitar el sexo oral y anal, además, se promueven actividades sexuales seguras como autoerotismo, sexo por internet, pareja sexual única y cercana (cónyuge) y actividades de higiene antes y después de la conducta sexual, incluyendo juguetes sexuales [60,61]. El Ministerio de Salud y Protección Social de Colombia se ha adherido a estas recomendaciones y las ha divulgado en su página oficial [62].

\section{Recomendaciones}

- Se recomiendan actividades sexuales seguras, evitando el contacto de saliva, moco y heces debido al riesgo de contagio de SARS-CoV-2.

\section{A favor fuerte}

- No se recomienda la práctica sexual a través de sexo oral o anal con una pareja que no conviva estrechamente.

\section{En contra fuerte}

- Se recomienda la realización de sexo por internet como alternativa segura de práctica sexual.

\section{A favor fuerte}

- Se recomienda mantener relaciones sexuales con una pareja segura o cónyuge.

\section{A favor fuerte}


- Se recomienda la higiene de manos antes y después del acto sexual.

\section{A favor fuerte}

- Se recomienda higiene corporal después del acto sexual.

\section{A favor fuerte}

- Se recomienda el lavado de juguetes sexuales antes y después de su uso.

\section{A favor fuerte}

\section{Contribución de los autores}

NY, GA, RB, EY, CG, AR, AA, JV, JR, RR, RT y KC participaron en el diseño y ejecución del consenso. Los demás autores participaron como expertos clínicos en la consulta de recomendaciones. Todos los autores participaron en la construcción del manuscrito y aprobaron su contenido.

\section{Conflicto de intereses}

Cada integrante del grupo desarrollador declaró el conflicto de intereses a través de un formato diseñado a priori, el cual se encuentra en custodia por el comité metodológico. Se realizó un análisis del posible impacto del conflicto en las recomendaciones.

Mercedes Alfaro ha recibido recursos de Shire (2016), Novordisk (2019) y Meak Sharp \& Dohme (2019); Javier Galeano ha recibido recursos de Fresenius, Abbott y Abbvie; Roberto Ramírez ha recibido recursos de Fresenius, Bohering, Nex Biolab y Abbvie; Carlos Rebolledo ha recibido recursos de Roche y Abbvie (2015); María José Vargas ha recibido recursos de RTS y Carlos Guido ha recibido recursos de TUTEUR y es miembro de Edit Advisory Board HeatlhSens. Los demás declararon no tener conflicto de interés.

\section{Independencia editorial}

Los autores declaran que existió independencia editorial con el organismo financiador, en cuyo caso la única función fue la financiación. 


\section{Grupo desarrollador}

\section{Dirección del consenso}

Nancy Yomayusa

\section{Comité directivo del consenso}

Nancy Yomayusa, Gustavo Aroca, Richard Baquero, Erica Yama, Camilo González, Adriana Robayo, Amaury Ariza, Juan Vargas, Jorge Rico, Roberto Ramírez y Rodolfo Torres.

\section{Comité metodológico}

Kelly Chacón

\section{Comité de expertos clínicos}

\section{Coordinador}

Roberto Ramírez

\section{Expertos clínicos}

Joaquín Rodelo, Héctor Mauricio Cárdenas, Álvaro Mercado, Hernando Altahona, Sandra Castelo, Mercedes Alfaro, Inge Arroyabe, Viviana Raoch, Elizabeth Ardila, Claudia Acosta, Roberto Ramírez e Ignacio Villanueva.

\section{Enfermería nefrológica}

\section{Coordinadores}

Diana Gayón, Jorge Pérez, Ingrid Torres, Carolina Pedraza, Natalia Carolina Tobón, Betty Zambrano, Jeniffer Fordon, Liseth Rincón, María Fernanda Pérez, Luisa Fernanda Grajales y Luis Chaparro Quiroz. 


\section{Equipo técnico-científico multidisciplinar}

\section{Geriatría}

Héctor Mauricio Cárdenas y Leidy Aristizábal (Asociación Colombiana de Geriatría).

\section{Nefrogeriatría}

Carlos Guido Musso.

\section{Cuidado paliativo}

María Victoria Mera, Gabriela Sarmiento, Sandra Liliana Parra y Paola Marcela Ruiz (Asociación Colombiana de Cuidado Paliativo). 


\section{Referencias}

[1] Cuenta de Alto Costo (CAC). Boletín de información técnica especializada de la cuenta de alto costo. 2018. $\uparrow$ Ver página 4

[2] Emami A, Javanmardi F, Pirbonyeh N, Akbari A. Prevalence of underlying diseases in hospitalized patients with COVID-19: A systematic review and meta-analysis. Arch Acad Emerg Med. 2020;8(1):e35. 个Ver página 4

[3] Zhang G, Hu C, Luo L, Fang F, Chen Y, Li J, et al. Clinical features and short-term outcomes of 221 patients with COVID-19 in Wuhan, China. J Clin Virol. [Internet]. 2020;127(mzo.):104364. Disponible en: https://doi.org/10.1016/j.jcv.2020.104364^Ver página

4

[4] Garg S, Kim L, Whitaker M, O’Halloran A, Cummings C, Holstein R, et al. Hospitalization Rates and Characteristics of Patients Hospitalized with Laboratory-Confirmed Coronavirus Disease 2019 - COVID-NET, 14 States, March 1-30, 2020. Morb Mortal Wkly Rep. 2020;69(15):458-64. $\uparrow$ Ver página 4

[5] Zhou F, Yu T, Du R, Fan G, Liu Y, Liu Z, et al. Clinical course and risk factors for mortality of adult inpatients with COVID-19 in Wuhan, China: A retrospective cohort study. Lancet [Internet]. 2020;395(10229):1054-62. Disponible en: http://x.doi.org/10.1016/S0140-6736(20) 30566-3 $\uparrow$ Ver páginas 4, 13

[6] Richardson S, Hirsch JS, Narasimhan M, Crawford JM, McGinn T, Davidson KW, et al. Presenting characteristics, comorbidities, and outcomes among 5700 patients hospitalized with COVID-19 in the New York City area. JAMA [Internet]. 2020 my. 26;323(20):2052-9. Disponible en: https://oi.org/10.1001/jama.2020.6775 个Ver páginas 4, 12, 13

[7] Perico L, Benigni A, Remuzzi G. Should Covid-19 concern nephrologists? why and to what extent? The emerging impasse of angiotensin blockade. Nephron. [Internet]. 2020; Disponible en: http:/www.embase.com/search/results? subaction=viewrecord\&from=export\&id= L631369382 个Ver página 4

[8] Rubin R. Finding ways to reduce coronavirus exposure during dialysis. JAMA. 2020;1-3. 个Ver página 4

[9] Palevsky PM, Radhakrishnan J, Townsend RR, Bakris GL, Forman JP. End- stage kidney disease. 2020;2019:1-18. $\uparrow$ Ver página 4 
[10] Sankrityayan H, Kale A, Sharma N, Anders HJ, Gaikwad AB. Evidence for use or disuse of renin-angiotensin system modulators in patients having COVID-19 with an underlying cardiorenal disorder. J Cardiovasc Pharmacol Ther. 2020;25(4):299-306. $\uparrow$ Ver páginas 4, 7

[11] Wang B, Li R, Lu Z, Huang Y. Does comorbidity increase the risk of patients with COVID-

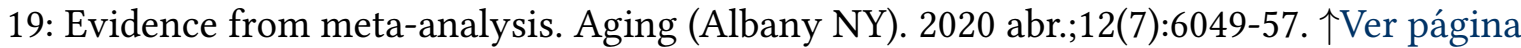
4

[12] Shahid Z, Kalayanamitra R, McClafferty B, Kepko D, Ramgobin D, Patel R, et al. COVID19 and older adults: What we know. J Am Geriatr Soc. 2020 abr.;68(5):926-29. ^Ver página 4

[13] Kreutz R, Algharably EA, Azizi M, Dobrowolski P, Guzik T, Januszewicz A, et al. Hypertension, the renin-angiotensin system, and the risk of lower respiratory tract infections and lung injury: Implications for COVID-19: European Society of Hypertension COVID19 Task Force Review of Evidence. Cardiovasc Res. [Internet]. 2020 abr. 15; Disponible en: https://oi.org/10.1093/cvr/cvaa097 个Ver páginas 4, 7

[14] Joanna Briggs Institute. The Joanna Briggs Institute scientific writer handbook. 2018;29. 个Ver página 5

[15] Sanabria AJ, Rigau D, Rotaeche R, Selva A, Marzo-Castillejo M, Alonso- Coello P. Sistema GRADE: Metodología para la realización de recomendaciones para la práctica clínica. Atención Primaria [Internet]. 2015;47(1):48-55. Disponible en: https:/doi.org/10.1016/ j.aprim.2013.12.013 $\uparrow$ Ver página 5

[16] South AM, Tomlinson L, Edmonston D, Hiremath S, Sparks MA. Controversies of reninangiotensin system inhibition during the COVID-19 pandemic. Nat Rev Nephrol. 2020 jun.;16(6):305-7. $\uparrow$ Ver páginas 6, 7

[17] Francisco ALM De, Canga JL. Coronavirus y riñón: aspectos epidemiologicos del covid-19. 2020;24. Disponible en: https:/www.nefrologiaaldia.org/ es-articulo-coronavirus-rinon-actualizacion-completa-25-305 $\uparrow$ Ver páginas 6, 9

[18] Rico-Mesa JS, White A, Anderson AS. Outcomes in patients with COVID-19 infection taking ACEI/ARB. Curr Cardiol Rep. [Internet]. 2020 abr. 14;22(5):31. Disponible en: https:/ doi.org/10.1007/s11886-020-01291-4 个Ver página 6

[19] Li J, Wang X, Chen J, Zhang H, Deng A. Association of renin-angiotensin system inhibitors with severity or risk of death in patients with hypertension hospitalized for coronavirus 
disease 2019 (COVID-19) infection in Wuhan, China. JAMA Cardiol. [Internet]. 2020 abr. 23. Disponible en: https://oi.org/10.1001/jamacardio.2020.1624 个Ver página 6

[20] de Abajo FJ, Rodríguez-Martín S, Lerma V, Mejía-Abril G, Aguilar M, García- Luque A, et al. Use of renin-angiotensin-aldosterone system inhibitors and risk of COVID-19 requiring admission to hospital: a case-population study. Lancet. 2020 my. 14;1705-14. $\uparrow$ Ver página 6

[21] Peng YD, Meng K, Guan HQ, Leng L, Zhu RR, Wang BY, et al. Clinical characteristics and outcomes of 112 cardiovascular disease patients infected by 2019-nCoV. Zhonghua Xin Xue Guan Bing Za Zhi [Chinese journal of cardiovascular diseases]. 2020 mzo.;48(0):E004. $\uparrow$ Ver página 6

[22] Singh AK, Gupta R, Misra A. Comorbidities in COVID-19: Outcomes in hypertensive cohort and controversies with renin angiotensin system blockers. Diabetes Metab Syndr. [Internet]. 2020 abr. 9;14(4):283-7. Disponible en: https:/doi.org/10.1016/j.dsx.2020. 03.016个Ver página 7

[23] Villanueva I, Ramírez R, Montejo J, Rodelo J, Puello L, Vélez M, et al. COVID-19 e hipertensión arterial: ¿existe evidencia para suspender antagonista sistema renina angiotensina? Rev Colomb Nefrol. [Internet]. 2020; 7(Supl.2):1-13. Disponible en: https://doi.org/10.22265/ acnef.7.Supl.2.405 $\uparrow$ Ver página

[24] Asociación Colombiana de Infectología. Consenso colombiano de atención, diagnóstico y manejo de la infección por SARS-COV-2/COVID-19. Rev Colomb Infectol. 2020;24:47. $\uparrow$ Ver página 7

[25] Bian J, Zhao R, Zhai S, Li Z. Anti-RAS drugs and SARS-CoV-2 infection. Acta Pharm Sin B [Internet]. 2020 jul.;10(7):1251-2. Disponible en: https://doi.org/10.1016/j.apsb.2020.04.013 个Ver página 7

[26] Kow CS, Zaidi STR, Hasan SS. Cardiovascular disease and use of renin- angiotensin system inhibitors in COVID-19. Am J Cardiovasc Drugs [Internet]. 2020 jun.;20(3):217-21. Disponible en: https://doi.org/10.1007/s40256-020-00406-0 个Ver página 7

[27] Zhang P, Zhu L, Cai J, Lei F, Qin J-J, Xie J, et al. Association of inpatient use of angiotensin converting enzyme inhibitors and angiotensin II receptor blockers with mortality among patients with hypertension hospitalized with COVID-19. Circ Res. 2020 jun. 5;126(12):167181. $\uparrow$ Ver página 7 
[28] Vaduganathan M, Vardeny O, Michel T, Mcmurray J, Pfeffer M, Solomon S. Special Report Renin - Angiotensin - Aldosterone system inhibitors in patients with Covid-19. N Engl J Med

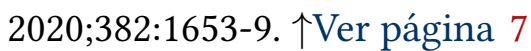

[29] Massachusetts General Hospital. Guía de tratamiento COVID-19. Massachusetts, Estados Unidos: MGH; 2020. 14 p. $\uparrow$ Ver página 7

[30] Berger J, Jaikaransingh V, Hedayati S. End-stage kidney disease in the elderly: Approach to dialysis initiation, choosing modality, and predicting outcomes. Adv Chronic Kidney Dis. 2016;23(1):36-43. 个Ver página 8

[31] Huang C, Wang Y, Li X, Ren L, Zhao J, Hu Y, et al. Clinical features of patients infected with 2019 novel coronavirus in Wuhan, China. Lancet. 2020;395(10223):497-506. $\uparrow$ Ver página 8

[32] Vergano M, Bertolini G, Giannini A, Gristina GR, Livigni S, Mistraletti G, et al. SIAARTI recommendations for the allocation of intensive care treatments in exceptional, resourcelimited circumstances. Minerva Anestesiol. 2020;1-8. $\uparrow$ Ver página 8

[33] Gómez-Batiste X, Turrillas P, Tebé C, Calsina-Berna A, Amblàs-Novellas J. NECPAL tool prognostication in advanced chronic illness: a rapid review and expert consensus. BMJ Support Palliat Care. 2020 abr. Disponible en: http:/doi.org/10.1136/bmjspcare-2019-002126个Ver página 8

[34] Sociedad Latinoamericana de Nefrología e Hipertensión. Recomendaciones para el manejo de pacientes portadores de enfermedad renal frente a la epidemia de coronavirus (COVID19). Nefro Latinoam. 2020;17. Disponible en: https:/www.apiinfectologia.org/wp-content/ uploads/2020/07/Savio-.-Nefro.Latinoam-2020171-6.pdf $\uparrow$ Ver página 9

[35] National Institute for Health and Care Excellence. COVID-19 rapid guideline: dialysis service delivery (NG160). NICE [Internet]. 2020 mzo. 20. Disponible en: https:/www.nice. org.uk/guidance/ng160 个Ver página 9

[36] Lidoriki I, Frountzas M, Schizas D. Could nutritional and functional status serve as prognostic factors for COVID-19 in the elderly? Med Hypotheses [Internet]. 2020 nov.;144:109946. Disponible en: https://doi.org/10.1016/j.mehy.2020.109946 个Ver página 10

[37] Chowdhury R, Peel NM, Krosch M, Hubbard RE. Frailty and chronic kidney disease: A systematic review. Arch Gerontol Geriatr [Internet]. 2017;68:135- 42. Disponible en: https:/ doi.org/10.1016/j.archger.2016.10.007 $\uparrow$ Ver página 10 
[38] Kallenberg MH, Kleinveld HA, Dekker FW, van Munster BC, Rabelink TJ, van Buren M, et al. Functional and cognitive impairment, frailty, and adverse health outcomes in older patients reaching ESRD-A systematic review. Clin J Am Soc Nephrol. [Internet]. 2016 sept. 7;11(9):1624-39. Disponible en: https://doi.org/10.2215/CJN.13611215 个Ver página 10

[39] Sy J, Johansen KL. The impact of frailty on outcomes in dialysis. Curr Opin Nephrol Hypertens. [Internet]. 2017 nov.;26(6):537-42. Disponible en: https://oi.org/10.1097/MNH. $0000000000000364 \uparrow$ Ver página 10

[40] Lee S, Lee S, Harada K, Bae S, Makizako H, Doi T, et al. Relationship between chronic kidney disease with diabetes or hypertension and frailty in community-dwelling Japanese older adults. Geriatr Gerontol Int. 2017 oct.;17(10):1527-33. ^Ver página 10

[41] National Institute for Health and Care Excellence. COVID-19 rapid guideline: critical care in adults. NICE [Internet]. 2020 mzo. 20. Disponible en: https:/www.nice.org.uk/guidance/ ng159 $\uparrow$ Ver página 10

[42] Montero-Odasso M, Hogan DB, Lam R, Madden K, MacKnight C, Molnar F, et al. Age alone is not adequate to determine healthcare resource allocation during the COVID-19 Pandemic. Can Geriatr J. 2020;23(1):152-4. 个Ver página 10

[43] Chong E, Chia JQ, Law F, Chew J, Chan M, Lim WS. Validating a standardised approach in administration of the clinical frailty scale in hospitalised older adults. Ann Acad Med Singapore. 2019 abr.;48(4):115-24. $\uparrow$ Ver página 11

[44] Dueñas E, Rojas A, Altamar G. Triage del adulto mayor con covid 19 en centro hospitalario. 2020. $\uparrow$ Ver página 11

[45] Le Maguet P, Roquilly A, Lasocki S, Asehnoune K, Carise E, Saint Martin M, et al. Prevalence and impact of frailty on mortality in elderly ICU patients: A prospective, multicenter, observational study. Intensive Care Med. 2014 my.;40(5):674-82. $\uparrow$ Ver página 11

[46] Kemenesi G, Kornya L, Tóth GE, Kurucz K, Zeghbib S, Somogyi BA, et al. Nursing homes and the elderly regarding the COVID-19 pandemic: situation report from Hungary. GeroScience [Internet]. 2020;2:1-7. Disponible en: https:/doi.org/10.1007/s11357-020-00195-z $\uparrow V e r$ página 11

[47] Naicker S, Yang CW, Hwang SJ, Liu BC, Chen JH, Jha V. The Novel Coronavirus 2019 epidemic and kidneys. Circulation [Internet]. 2020;97(5):824-8. Disponible en: https:/doi. org/10.1016/j.kint.2020.03.001 个Ver página 13 
[48] DeFilippis EM, Ranard LS, Berg DD. Cardiopulmonary resuscitation during the COVID19 pandemic: A view from trainees on the frontline. Circulation. 2020;1-8. $\uparrow$ Ver páginas 13, 14

[49] Crook P. Cardiopulmonary resuscitation in the COVID-19 era - Will the risk- benefit shift in resource-poor settings? Resuscitation [Internet]. 2020;151:118. Disponible en: https: //doi.org/10.1016/j.resuscitation.2020.04.016 ^Ver página 13

[50] Chong E, Chan M, Tan HN, Lim WS. COVID-19: Use of the clinical frailty scale for critical care decisions. J Am Geriatr Soc. [Internet]. 2020 jun.;68(6):E30-2. Disponible en: https:// doi.org/10.1111/jgs.16528个Ver página 13

[51] Resuscitation Council UK [sitio virtual]. Londres: Resucitation Council UK; 2020. Statements and resources on COVID 19 (Coronavirus), CPR and Resuscitation. Disponible en: https:/www.resus.org.uk/covid-19-resources $\uparrow$ Ver página 14

[52] Cappuccio FP. Confusion over CPR in patients with Covid-19. BMJ. [Internet]. 2020 my. 6;369:m1805. Disponible en: https://doi.org/10.1136/bmj.m1805 个Ver página 14

[53] Qiu J, Shen B, Zhao M, Wang Z, Xie B, Xu Y. A nationwide survey of psychological distress among Chinese people in the COVID-19 epidemic: implications and policy recommendations. Gen psychiatry. [Internet]. 2020 mzo. 6;33(2):e100213-e100213. Disponible en: https://doi.org/10.1136/gpsych-2020-100213 个Ver página 14

[54] Wang C, Pan R, Wan X, Tan Y, Xu L, Ho CS, et al. Immediate psychological responses and associated factors during the initial stage of the 2019 coronavirus disease (COVID-19) epidemic among the general population in China. Int J Environ Res Public Health. 2020;17(5). 个Ver página 14, 15

[55] Ho CS, Chee CY, Ho RC. Mental health strategies to combat the psychological impact of COVID-19 beyond paranoia and panic. Ann Acad Med Singapore. 2020;49(1):1-3. $\uparrow$ Ver página 15

[56] Holmes EA, O’Connor RC, Perry VH, Tracey I, Wessely S, Arseneault L, et al. Multidisciplinary research priorities for the COVID-19 pandemic: A call for action for mental health science. Lancet Psychiatry. [Internet]. 2020;7(6):547- 60. Disponible en: https://oi.org/ 10.1016/S2215-0366(20)30168-1 个Ver página 15

[57] Lima CK, Carvalho PM, Silva I, de Oliveira JV, Saraiva JS, de Souza RI, et al. The emotional impact of Coronavirus 2019-nCoV (new Coronavirus disease). Psychiatry Res [Internet]. 
2020;287:112915. Disponible en: https://oi.org/10.1016/j.psychres.2020.112915 个Ver página 15

[58] Goodman-Casanova JM, Dura-Perez E, Guzman-Parra J, Cuesta-Vargas A, MayoralCleries F. Telehealth home support during COVID-19 confinement for community-dwelling older adults with mild cognitive impairment or mild dementia: Survey study. J Med Internet Res. 2020 my.;22(5):e19434. $\uparrow V e r$ página 15

[59] Wu Z, Zhang Z, Wu S. Focus on the crosstalk between COVID-19 and urogenital systems. J Urol. 2020 abr. 3. Disponible en: https:/dx.doi.org/10.1097\%2FJU.0000000000001068 个Ver página 16

[60] The Official Website of the City of New York [Internet]. Nueva York: NYC Health; 2020 ag. 6. Sex and COVID-19 Fact Sheet. Disponible en: https:/www1.nyc.gov/assets/doh/ downloads/pdf/imm/covid-sex-guidance.pdf $\uparrow$ Ver página 16

[61] Ramírez R, Villanueva B, Gomez F. ¿Cuáles son las recomendaciones sobre sexualidad en el paciente adulto mayor multimórbido con enfermedad renal crónica, en la pandemia del Covid-19? Colomb Nefrol. 2020;7. ^Ver página 16

[62] Ministerio de Salud y Protección Social [Internet]. Colombia: Minsalud; 2020 mzo. 27. ABC sobre las relaciones sexuales y la enfermedad por Coronavirus (Covid-19) [citado 2020 oct. 10]. Disponible en: https:/www.minsalud.gov.co/Paginas/ ABC-sobre-las-relaciones-sexuales-y-las-enfermedades-por-coronavirus-(COVID-19) .aspx $\uparrow$ Ver página 16

[63] Yomayusa N, Yama E, González C, Ariza A, Aroca G, Baquero R, et al. Consenso colombiano de expertos sobre recomendaciones informadas en la evidencia para la prevención, diagnóstico y manejo de infección por SARS-CoV-2/COVID-19 en pacientes con Enfermedad Renal Crónica en diálisis. Rev. Colomb. Nefrol. 7(Supl.2). Disponible en: https:/ revistanefrologia.org/index.php/rcn/article/view/474 个Ver página 9, 10 


\section{Anexos}

\section{Anexo A. Evaluación de calidad de documentos incluido}

\begin{tabular}{|c|c|c|}
\hline Documento (\# referencia bibliográfica) & \begin{tabular}{|c|c|}
$\begin{array}{c}\text { Tipo de } \\
\text { documento }\end{array}$ \\
\end{tabular} & $\begin{array}{l}\begin{array}{c}\text { Evaluación } \\
\text { de calidad }\end{array} \\
\end{array}$ \\
\hline 1 & Informe & N/A \\
\hline 2 & $\begin{array}{l}\text { Revisión } \\
\text { sistemática }\end{array}$ & $\begin{array}{l}\text { Baja } \\
\text { confianza }\end{array}$ \\
\hline 3 & Serie de casos & $\begin{array}{l}\text { Cumple } \\
\text { reporte JBI }\end{array}$ \\
\hline 4 & $\begin{array}{l}\text { Reporte } \\
\text { técnico }\end{array}$ & N/A \\
\hline 5 & $\begin{array}{l}\text { Estudio de } \\
\text { cohorte }\end{array}$ & Moderada \\
\hline 6 & Serie de casos & $\begin{array}{l}\text { Cumple } \\
\text { reporte JBI }\end{array}$ \\
\hline 7 & $\begin{array}{l}\text { Revisión } \\
\text { narrativa }\end{array}$ & Baja calidad \\
\hline 8 & Punto de vista & N/A \\
\hline 9 & $\begin{array}{l}\text { Recomendacio } \\
\text { nes }\end{array}$ & N/A \\
\hline 10 & $\begin{array}{l}\text { Revisión de } \\
\text { tema }\end{array}$ & N/A \\
\hline 11 & $\begin{array}{l}\text { Revisión } \\
\text { sistemática }\end{array}$ & $\begin{array}{l}\text { Baja } \\
\text { confianza }\end{array}$ \\
\hline 12 & Revisión de & N/A \\
\hline
\end{tabular}




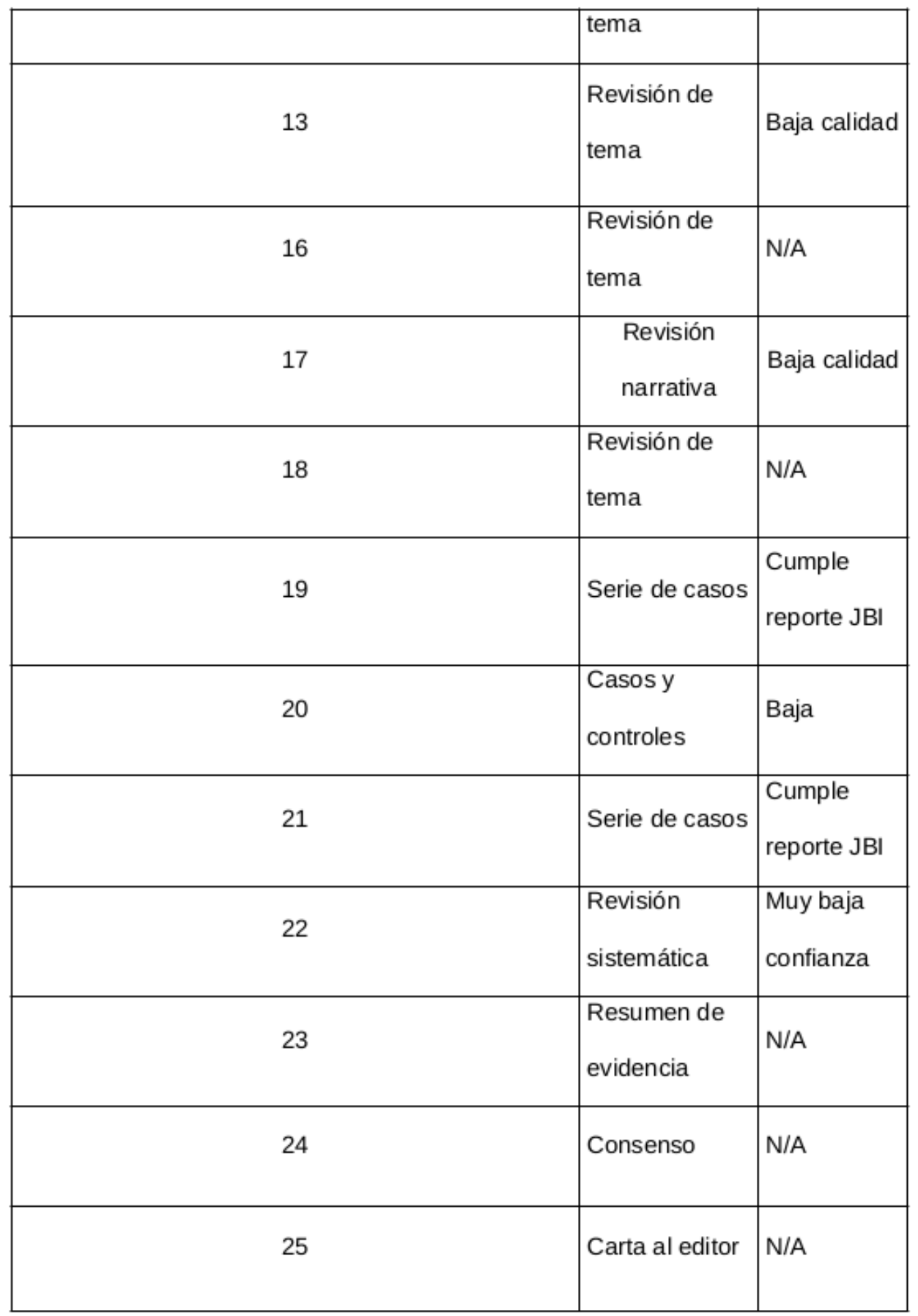




\begin{tabular}{|c|c|c|}
\hline 26 & $\begin{array}{l}\text { Resumen de } \\
\text { evidencia }\end{array}$ & N/A \\
\hline 27 & Serie de casos & $\begin{array}{l}\text { Cumple } \\
\text { reporte JBI }\end{array}$ \\
\hline 28 & $\begin{array}{l}\text { Revisión de } \\
\text { tema }\end{array}$ & N/A \\
\hline 29 & $\begin{array}{l}\text { Recomendacio } \\
\text { nes }\end{array}$ & N/A \\
\hline 30 & $\begin{array}{l}\text { Revisión de } \\
\text { tema }\end{array}$ & N/A \\
\hline 31 & $\begin{array}{l}\text { Corte } \\
\text { transversal } \\
\text { analítico }\end{array}$ & Baja \\
\hline 32 & $\begin{array}{l}\text { Recomendacio } \\
\text { nes }\end{array}$ & N/A \\
\hline 33 & $\begin{array}{l}\text { Revisión } \\
\text { rápida }\end{array}$ & Baja calidad \\
\hline 34 & $\begin{array}{l}\text { Consenso } \\
\text { informal }\end{array}$ & N/A \\
\hline 35 & Guía rápida & Moderada \\
\hline 37 & $\begin{array}{l}\text { Revisión } \\
\text { sistemática }\end{array}$ & $\begin{array}{l}\text { Confianza } \\
\text { media }\end{array}$ \\
\hline
\end{tabular}




\begin{tabular}{|c|c|c|}
\hline 38 & $\begin{array}{l}\text { Revisión } \\
\text { sistemática }\end{array}$ & $\begin{array}{l}\text { Confianza } \\
\text { media }\end{array}$ \\
\hline 39 & $\begin{array}{l}\text { Revisión de } \\
\text { tema }\end{array}$ & N/A \\
\hline 40 & $\begin{array}{l}\text { Corte } \\
\text { transversal } \\
\text { analítico }\end{array}$ & $\begin{array}{l}\text { No cumple } \\
\text { reporte JB }\end{array}$ \\
\hline 41 & Guía rápida & Moderada \\
\hline 43 & $\begin{array}{l}\text { Estudio de } \\
\text { prueba } \\
\text { diagnóstica }\end{array}$ & N/A \\
\hline 44 & $\begin{array}{l}\text { Manuscrito en } \\
\text { vía de } \\
\text { publicación }\end{array}$ & N/A \\
\hline 45 & $\begin{array}{l}\text { Corte } \\
\text { transversal } \\
\text { analítico }\end{array}$ & $\begin{array}{l}\text { Cumple } \\
\text { reporte JB }\end{array}$ \\
\hline 46 & Informe & N/A \\
\hline 47 & $\begin{array}{l}\text { Revisión } \\
\text { narrativa }\end{array}$ & N/A \\
\hline 48 & Punto de vista & N/A \\
\hline
\end{tabular}




\begin{tabular}{|c|c|c|}
\hline 49 & Carta al editor & N/A \\
\hline 52 & Carta al editor & N/A \\
\hline 51 & $\begin{array}{l}\text { Recomendacio } \\
\text { nes }\end{array}$ & N/A \\
\hline 53 & $\begin{array}{l}\text { Corte } \\
\text { transversal }\end{array}$ & N/A \\
\hline 54 & $\begin{array}{l}\text { Corte } \\
\text { transversal }\end{array}$ & N/A \\
\hline 55 & Comentario & N/A \\
\hline 56 & $\begin{array}{l}\text { Consenso } \\
\text { informal }\end{array}$ & N/A \\
\hline 57 & Carta al editor & N/A \\
\hline 58 & $\begin{array}{l}\text { Corte } \\
\text { transversal }\end{array}$ & $\begin{array}{l}\text { Cumple } \\
\text { reporte JBI }\end{array}$ \\
\hline 59 & Editorial & $\mathrm{N} / \mathrm{A}$ \\
\hline 60 & $\begin{array}{l}\text { Recomendacio } \\
\text { nes }\end{array}$ & N/A \\
\hline 61 & $\begin{array}{l}\text { Recomendacio } \\
\text { nes }\end{array}$ & N/A \\
\hline 62 & Informe & N/A \\
\hline 42 & Guía rápida & Baja \\
\hline
\end{tabular}

Fuente: elaboración propia. 


\section{Anexo B. Resultados de la consulta por cada recomendación}

\begin{tabular}{|c|c|}
\hline Recomendación & $\begin{array}{l}\text { Resultado consulta } \\
(\%)\end{array}$ \\
\hline $\begin{array}{l}\text { Se recomienda: [Continuar esquemas de tratamiento } \\
\text { basados en IECA y ARA-2 en pacientes con } \\
\text { indicación para su uso.] }\end{array}$ & 100,00 \\
\hline $\begin{array}{l}\text { Se recomienda: [Considerar la patología de base que } \\
\text { justifica el uso del medicamento y el estado actual del } \\
\text { paciente para considerar modificación o suspensión } \\
\text { temporal del tratamiento instaurado.] }\end{array}$ & 95,24 \\
\hline $\begin{array}{l}\text { Se recomienda: [Informar a los pacientes sobre su } \\
\text { tratamiento y alentarlos a no cambiar o suspender la } \\
\text { medicación, a menos que sea indicado por el médico } \\
\text { tratante.] }\end{array}$ & 100,00 \\
\hline $\begin{array}{l}\text { En caso de: [Daño renal agudo, hipotensión o } \\
\text { contraindicación de uso, se recomienda suspender } \\
\text { temporalmente los IECA y ARA-2.] }\end{array}$ & 100,00 \\
\hline $\begin{array}{l}\text { Se recomienda: [Considerar el pronóstico del paciente } \\
\text { y realizar análisis individualizado de los riesgos y los }\end{array}$ & 100,00 \\
\hline
\end{tabular}




\begin{tabular}{|c|c|}
\hline $\begin{array}{l}\text { beneficios de la TST, además de las preferencias de } \\
\text { los pacientes y sus cuidadores frente a las opciones } \\
\text { de cuidado en circunstancias de mal pronóstico o final } \\
\text { de la vida.] }\end{array}$ & \\
\hline $\begin{array}{l}\text { Se sugiere: [Suspender la hemodiálisis en pacientes } \\
\text { que cumplan los criterios clínicos y analíticos de mal } \\
\text { pronóstico, independientemente de su edad según los } \\
\text { criterios de Necpal.] }\end{array}$ & 95,24 \\
\hline $\begin{array}{l}\text { Se recomienda: [Evitar la remisión a servicios de } \\
\text { urgencias para pacientes con ERC, a menos de que } \\
\text { exista empeoramiento de condición general o } \\
\text { condiciones como pielonefritis, trauma renal, eventos } \\
\text { vasculares en arteria o vena renal o trastornos } \\
\text { hidroelectrolíticos que requieran monitorización } \\
\text { continua, los cuales no puedan ser manejados en las } \\
\text { unidades renales o de diálisis.] }\end{array}$ & 90,48 \\
\hline $\begin{array}{l}\text { Se recomienda: [La medición de funcionalidad y } \\
\text { fragilidad en el adulto mayor con Covid-19 y } \\
\text { considerar sus hallazgos en la actuación clínica.] }\end{array}$ & 100,00 \\
\hline $\begin{array}{l}\text { Se recomienda: [El uso del índice de Barthel como } \\
\text { herramienta estandarizada y pragmática en la } \\
\text { medición de funcionalidad de adulto mayor.] }\end{array}$ & 100,00 \\
\hline $\begin{array}{l}\text { Se recomienda: [El uso de escalas de fragilidad como } \\
\text { la escala Frail o la CFS en pacientes con Covid-19 y }\end{array}$ & 100,00 \\
\hline
\end{tabular}




\begin{tabular}{|c|c|}
\hline $\begin{array}{l}\text { ERC, con base en la situación clínica en que se } \\
\text { encontraban dos semanas antes de los síntomas de } \\
\text { infección por covid-19 para orientar la conducta clínica } \\
\text { en UCl.] }\end{array}$ & \\
\hline $\begin{array}{l}\text { Se recomienda: [Informar al paciente acerca del } \\
\text { mecanismo de toma de decisiones basado en la CFS, } \\
\text { teniendo en cuenta el riesgo de contagio masivo en } \\
\text { centros de protección social.] }\end{array}$ & 100,00 \\
\hline $\begin{array}{l}\text { Se sugiere: [Para pacientes con puntuación en CFS } \\
\text { igual a 5, sea el geriatra quien realice una evaluación } \\
\text { multidimensional en los diferentes dominios (médico, } \\
\text { funcional, cognición, afecto, riesgo social) para definir } \\
\text { los objetivos terapéuticos en cada persona mayor. En } \\
\text { caso de no contar con este recurso humano, se } \\
\text { recomienda realizar un análisis por equipo } \\
\text { interdisciplinario, teniendo en cuenta la severidad de } \\
\text { la patología y las voluntades anticipadas en la toma } \\
\text { de decisiones.] }\end{array}$ & 100,00 \\
\hline $\begin{array}{l}\text { Se sugiere que: [Los adultos mayores } \\
\text { institucionalizados reciban el mismo enfoque en toma } \\
\text { de decisiones según la CFS.] }\end{array}$ & 100,00 \\
\hline $\begin{array}{l}\text { Se sugiere: [La aplicación del índice de Charlson } \\
\text { como herramienta pronóstica en pacientes con Covid- } \\
19 \text { y ERC, cuando la CFS se encuentre en }\end{array}$ & 100,00 \\
\hline
\end{tabular}




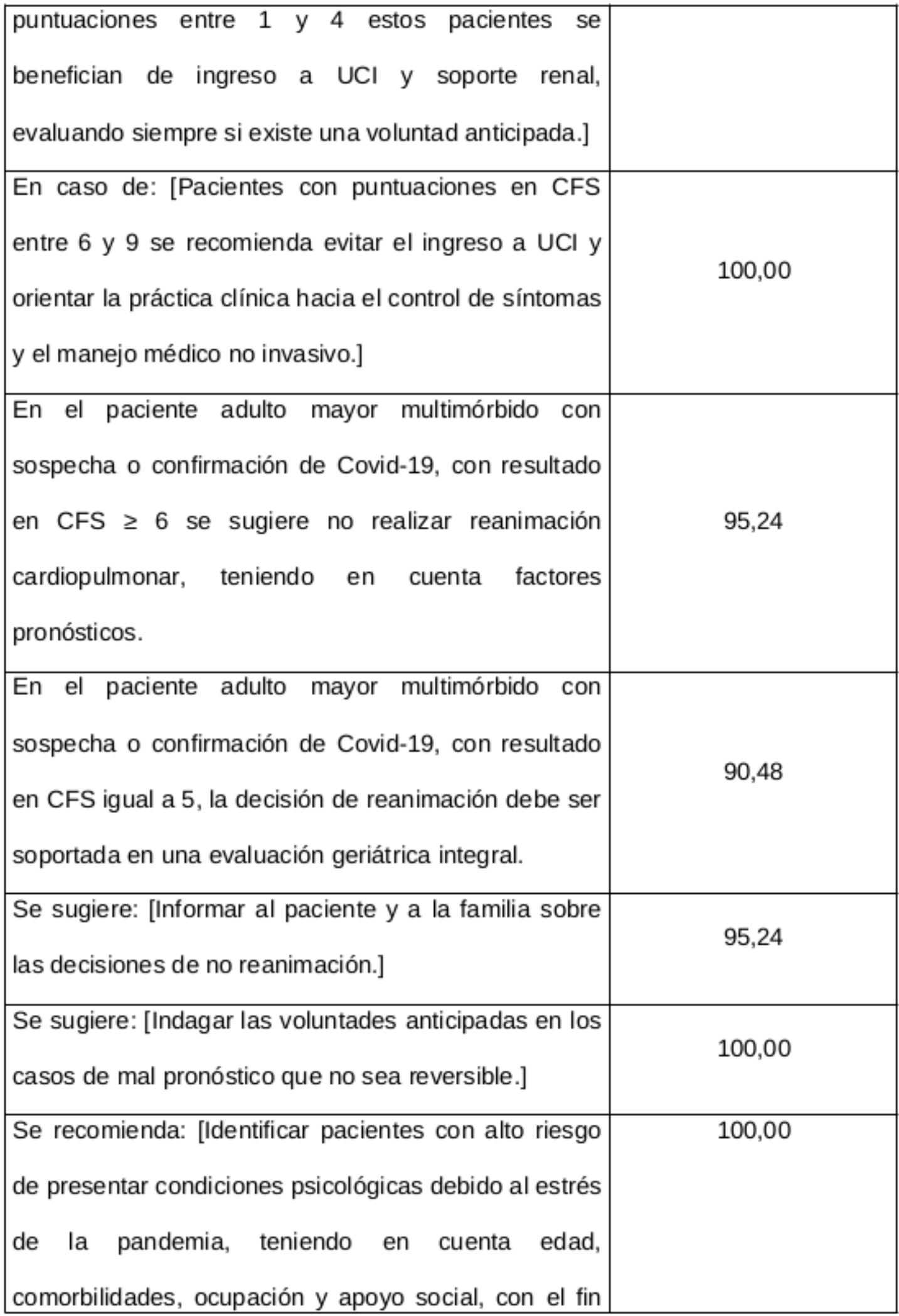




\begin{tabular}{|c|c|}
\hline de iniciar intervenciones tempranas.] & \\
\hline $\begin{array}{l}\text { Se recomienda: [El acompañamiento de trabajo social } \\
\text { para paciente en soledad.] }\end{array}$ & 100,00 \\
\hline $\begin{array}{l}\text { Se recomienda: [EI uso de herramientas tecnológicas } \\
\text { que faciliten la realización de las intervenciones.] }\end{array}$ & 100,00 \\
\hline $\begin{array}{l}\text { Se recomienda: [Continuar hábitos de vida en la } \\
\text { medida de lo posible o generar una nueva rutina } \\
\text { durante la pandemia por Covid-19.] }\end{array}$ & 100,00 \\
\hline $\begin{array}{l}\text { Se recomienda: [Incentivar el autocuidado en el adulto } \\
\text { mayor.] }\end{array}$ & 100,00 \\
\hline $\begin{array}{l}\text { Se recomienda: [La realización de actividades físicas } \\
\text { y cognitivas ajustadas a la edad y a la condición } \\
\text { física.] }\end{array}$ & 100,00 \\
\hline $\begin{array}{l}\text { Se recomienda: [Actividades sexuales seguras, } \\
\text { evitando el contacto de saliva, moco y heces debido al } \\
\text { riesgo de contagio de SARS-CoV-2.] }\end{array}$ & 100,00 \\
\hline $\begin{array}{l}\text { Se recomienda: [La realización de sexo por internet } \\
\text { como alternativa segura de práctica sexual.] }\end{array}$ & 90,48 \\
\hline $\begin{array}{l}\text { Se recomienda: [Mantener relaciones sexuales con } \\
\text { una pareja segura o cónyuge.] }\end{array}$ & 100,00 \\
\hline $\begin{array}{l}\text { Se recomienda: [La higiene de manos antes y } \\
\text { después del acto sexual.] }\end{array}$ & 100,00 \\
\hline
\end{tabular}




\begin{tabular}{|l|c|}
\hline Se recomienda: [Higiene corporal después del acto & 100,00 \\
\hline sexual.] & 100,00 \\
\hline y después de su uso.] & 100,00 \\
\hline No se recomienda: [La práctica sexual a través de & 100 conviva \\
sexo oral o anal con una pareja que no convies & \\
\hline
\end{tabular}

Fuente: elaboración propia. 


\section{Lista completa de autores}

Roberto Ramírez (iD) 1 , Nancy Yomayusa (iD 1,2, Camilo González (iD) 1,3, Erika Yama (D) 1,2,3, Juan Guillermo Vargas (D) 1 , Jorge Rico (iD 1,4, Amaury Ariza (D) 1,5, Gustavo Aroca (iD 1,6, Richard Baquero iD 7,8, Kelly Chacón (D) 2 , Rodolfo Torres (iD) 1 , Adriana Robayo (D) 1 , Álvaro Mercado iD ${ }^{9}$, Carlos Rebolledo (D) ${ }^{9}$, Diana Gayón ${ }^{3}$, Héctor Cárdenas (iD 10 , Ignacio Villanueva (iD) 1 , Ingrid Raoch (iD ${ }^{11}$, Javier Galeano (iD 9 , Jorge Coronado Daza (iD 12,13,

Leidy Aristizábal iD 14, María José Vargas (DD 15, Martha Patricia Rodríguez (iD 16,17, Mercedes Alfaro (iD 1,18, Natalia Tobón ${ }^{1,19}$, Rodrigo Daza (iD 4, Carlos Musso (iD20, María Victoria Mera ${ }^{21}$

${ }^{1}$ Capítulo de nefrogeriatría, Asociación Colombiana de Nefrología e Hipertensión Arterial, Bogotá, Colombia.

${ }^{2}$ Grupo de Investigación Traslacional IGEC, Unisanitas-Keralty, Bogotá, Colombia.

${ }^{3}$ Unidad Renal Sanitas, Clínica Colsanitas, Bogotá, Colombia.

${ }^{4}$ Fresenius Medical Care, Colombia. ${ }^{5}$ Baxter, Colombia.

${ }^{6}$ Universidad Simón Bolívar, Barranquilla, Colombia.

${ }^{7}$ Asociación Colombiana de Nefrología Pediátrica.

${ }^{8}$ Hospital Universitario San Vicente Fundación, Medellín, Colombia.

${ }^{9}$ Davita, Colombia.

${ }^{10}$ Keralty, Bogotá, D.C., Colombia.

${ }^{11}$ FMEPREVER, Colombia.

${ }^{12}$ Universidad de Cartagena, Cartagena, Colombia.

${ }^{13}$ Nefrología y Diálisis S.A.S, Cartagena, Colombia.

${ }^{14}$ Fundación Valle del Lili, Cali, Colombia.

${ }^{15}$ Renal Therapy Services RTS, Colombia.

${ }^{16}$ Asociación Colombiana Medicina Interna.

${ }^{17}$ Pontifica Universidad Javeriana, Bogotá, D.C., Colombia.

${ }^{18}$ Corporación Universitaria Rafael Núñez de Cartagena, Cartagena, Colombia.

${ }^{19}$ Hospital Universitario del Valle, Cali, Colombia.

${ }^{20}$ Instituto Universitario Hospital Italiano de Buenos Aires, Buenos Aires, Argentina.

${ }^{21}$ Asociación Colombiana de Cuidado Paliativo.

${ }^{22}$ Universidad Santiago de Cali, Cali, Colombia. 